ARTICLE

https://doi.org/10.1038/s41467-018-07331-6

\title{
Fluorine-free water-in-ionomer electrolytes for sustainable lithium-ion batteries
}

\author{
Xin He (1) ${ }^{1}$, Bo Yan ${ }^{1}$, Xin Zhang ${ }^{2}$, Zigeng Liu ${ }^{3}$, Dominic Bresser ${ }^{4,8}$, Jun Wang ${ }^{5}$, Rui Wang ${ }^{6}$, Xia Cao ${ }^{5}$, \\ Yixi Su${ }^{6}$, Hao Jia ${ }^{5}$, Clare P. Grey ${ }^{3}$, Henrich Frielinghaus (1) ${ }^{6}$, Donald G. Truhlar (1) ${ }^{7}$, Martin Winter ${ }^{1,5}$, \\ Jie $\mathrm{Li}^{5} \&$ Elie Paillard
}

The continuously increasing number and size of lithium-based batteries developed for largescale applications raise serious environmental concerns. Herein, we address the issues related to electrolyte toxicity and safety by proposing a "water-in-ionomer" type of electrolyte which replaces organic solvents by water and expensive and toxic fluorinated lithium salts by a non-fluorinated, inexpensive and non-toxic superabsorbing ionomer, lithium polyacrylate. Interestingly, the electrochemical stability window of this electrolyte is extended greatly, even for high water contents. Particularly, the gel with 50 wt\% ionomer exhibits an electrochemical stability window of $2.6 \mathrm{~V}$ vs. platinum and a conductivity of $6.5 \mathrm{mS} \mathrm{cm}^{-1}$ at $20^{\circ} \mathrm{C}$. Structural investigations suggest that the electrolytes locally self-organize and most likely switch local structures with the change of water content, leading to a $50 \%$ gel with good conductivity and elastic properties. $\mathrm{A} \mathrm{LiTi} 2\left(\mathrm{PO}_{4}\right)_{3} / \mathrm{LiMn}_{2} \mathrm{O}_{4}$ lithium-ion cell incorporating this electrolyte provided an average discharge voltage $>1.5 \mathrm{~V}$ and a specific energy of $77 \mathrm{Wh} \mathrm{kg}^{-1}$, while for an alternative cell chemistry, i.e., $\mathrm{TiO}_{2} / \mathrm{LiMn}_{2} \mathrm{O}_{4}$, a further enhanced average output voltage of $2.1 \mathrm{~V}$ and an initial specific energy of $124.2 \mathrm{Wh} \mathrm{kg}^{-1}$ are achieved.

\footnotetext{
${ }^{1}$ Helmholtz Institute Münster - Forschungszentrum Jülich GmbH (IEK 12), Corrensstrasse 46, 48149 Münster, D-48149 Münster, Germany. ${ }^{2}$ State Key Laboratory of Chemical Resource Engineering, Institute of Materia Medica, College of Science, Beijing University of Chemical Technology, Beijing 100029, P. R. China. ${ }^{3}$ Department of Chemistry, University of Cambridge, Lensfield Road, Cambridge CB2 1EW, UK. ${ }^{4}$ University Grenoble Alpes, CEA, CNRS, SyMMES, F-38000 Grenoble, France. ${ }^{5}$ MEET Battery Research Center, Institute of Physical Chemistry, University of Münster, Corrensstraße 46, D-48149 Münster, Germany. ${ }^{6}$ Jülich Centre for Neutron Science at MLZ, Forschungszentrum Jülich GmbH, Lichtenbergstrasse 1, D-85747 Garching, Germany. ${ }^{7}$ Department of Chemistry, Chemical Theory Center, and Minnesota Supercomputing Institute, University of Minnesota, Minneapolis, Minnesota 55455-0431, USA. ${ }^{8}$ Present address: Karlsruhe Institute of Technology (KIT), Helmholtzstrasse 11, $89081 \mathrm{Ulm}$, Germany. Correspondence and requests for materials should be addressed to X.Z. (email: zhangxin@mail.buct.edu.cn) or to J.L. (email: jie.li@uni-muenster.de) or to E.P. (email: e.paillard@fz-juelich.de)
} 
ithium-ion batteries are now used in electric vehicles and are under study for electric grid stabilization to allow for a larger portion of the electric power supply to be derived from renewable, but intermittent, energy sources ${ }^{1}$. However, as battery size increases, so do their environmental impact and associated risks. Besides the toxic and costly transition metals, such as $\mathrm{Ni}$ and Co used in cathodes, key concerns are the flammability and toxicity of the electrolyte ${ }^{2}$. Thus, the use of non-flammable and nontoxic electrolytes would be desirable. In recent research, various alternative electrolytes were proposed. In particular, highly concentrated electrolytes having no "free" solvent molecules present characteristics that differ significantly from their "diluted" $1 \mathrm{M}$ counterparts, especially concerning their electrochemical stability window $(\mathrm{ESW})^{3}$. Among them, "polymer-insalt" electrolytes ${ }^{4}$ were proposed to take advantage of the high solubility of low lattice energy Li salts, such as lithium bis(trifluoromethanesulfonyl)imide (LiTFSI) in polyethylene oxide ${ }^{5,6}$. Unfortunately, despite some attempts at developing nonfluorinated anions ${ }^{7-12}$, low lattice energy organic $\mathrm{Li}$ salts are usually heavily fluorinated, toxic (LiTFSI has a LD50 (oral, rat) of $160 \mathrm{mg} \mathrm{kg}^{-1}$, according to the material saftey datasheet of Solvay (https://www.solvay.us/en/binaries/PRC90029263-USA-340548.

pdf)), and environmentally persistent. More recently, a variety of solvents, including glymes ${ }^{13,14}$, cyclic ethers ${ }^{15}$, and acetonitrile ${ }^{16}$, have been used in "solvent-in-salt" electrolytes with LiTFSI as lithium salt. In most cases though, this approach increases the fluorine content of the electrolyte, and although LiTFSI could potentially be recycled ${ }^{17}$, increases the price and toxicity of the electrolyte. Another approach consists in developing a lithiumion chemistry that would accommodate an aqueous electrolyte ${ }^{18,19}$, which could-in addition to the advantages it brings in terms of safety-overcome the use of expensive and fluorinated anions due to the excellent solvating properties of water. A significant problem, however, is that water limits the ESW. Nevertheless, the $1.23 \mathrm{~V}$ "thermodynamic" ESW of water can be exceeded in many cases. For instance, Suo et al. ${ }^{20}$ and Dong et al. ${ }^{21}$ proposed a "water-in-salt" electrolyte with a $21 \mathrm{~m}$ solution of LiTFSI in water, later extended to mixtures of perfluorinated $\mathrm{Li}$ salts ${ }^{20,22,23}$, providing an outstanding ESW and battery output voltages of 2 to $3 \mathrm{~V}$. Nonetheless, although the flammability issue is solved and the performance greatly improved, the fluorine content is, in those cases, much higher than in conventional lithium-ion electrolytes.

Here, we propose a type of electrolyte: A "water-in-ionomer", non-fluorinated, and non-toxic ionomeric aqueous gel electrolyte that, although being derived from a weak acid and incorporating a relatively high water fraction, exhibits properties similar to those of "water-in-salt" electrolytes for operating Li-ion batteries with voltages far beyond water ESW.

\section{Results}

From dry ionomers and "solvent-in-salt" to "water-in-ionomer" electrolytes. Ionomers ${ }^{24-27}$, (i.e., lithium salts with the anionic moiety bound to a polymer backbone), providing that they can offer sufficient $\mathrm{Li}^{+}$mobility, would offer several advantages, such as high $\mathrm{Li}^{+}$transference numbers, and thus limited concentration gradients and $\mathrm{Li}$ dendrites growth ${ }^{28}$. One of the greatest challenges for these ionomers, though, is their complex preparation, given that the ionic function should allow for facile dissociation (thus, preferentially incorporating an fluorinated anionic moiety) and, for "dry" polymer electrolytes, one requires interspacing solvating units that simultaneously possesses high segmental mobility to ensure ionic dissociation and conduction. However, when ionomers are mixed with a lowviscosity solvent allowing high dissociation of the ionic moiety and high mobility, there is no longer a need for intrinsic solvation and mobility. Hence, the use of water as plasticizer and co-solvent for ionomers should allow using cheaper and non-fluorinated anionic moieties. This points to single block ionomers, such as polyacrylic acid (PAA) which is inexpensive and commercially widespread (used in disposable diapers) and whose non-toxic sodium salt has been listed as food additive by the FDA ${ }^{29}$.

The lithiated form (LiPAA) PAA was evaluated in aqueous gels. Figure 1a shows that gels with excellent dimensional stability are obtained for $50 \mathrm{wt} \%$ of LiPAA and above. However, the $70 \%$ gel is rather rigid (which leads to contact issues in cells) and includes bubbles, thus is difficult to process. The evolution of the storage and loss modulus of the gels (Fig. 1b), detailed in Supplementary Note 1 , shows that the $50 \mathrm{wt} \%$ gel deviates from the general trend, with a more elastic behavior (i.e., $\tan \delta=\mathrm{G}^{\prime} / \mathrm{G}^{\prime \prime}$ $>1$ ) on the whole deformation range as well as an increase of the storage modulus with increasing deformation. Figure 1c shows the conductivity of the electrolytes which follow a Vogel-Tammann-Fulcher (VTF) behavior (the VTF parameters are reported in Supplementary Table 2 and are discussed in Supplementary Note 2). The $50 \mathrm{wt} \%$ LiPAA gel exhibits $6.5 \mathrm{mS}$ $\mathrm{cm}^{-1}$ at $20^{\circ} \mathrm{C}$, similarly to organic carbonate-based lithium-ion electrolytes $(\sigma=5-11 \mathrm{mS} \mathrm{cm}-1)^{30}$, which is especially high considering that the anionic movement is limited in the electrolyte $\left(\mathrm{a} \mathrm{Li}^{+}\right.$transference number $\left(\mathrm{T}^{+}\right)$of 0.77 has been determined by pulse-field gradient NMR (PFG-NMR) (see Supplementary Note 3 and Supplementary Table 5 for other $\mathrm{T}^{+}$ values). As presented in Fig. 1d, the ESW of the electrolytes evolves with the polymer content in a similar trend as reported for "water-in-salt" electrolytes ${ }^{20}$. A first reduction starts at rather high potential (ca. $3.5 \mathrm{~V}$ vs. $\mathrm{Li} / \mathrm{Li}^{+}$for the ${ }^{14} \mathrm{wt} \% \mathrm{LiPAA}$ electrolyte). This is above hydrogen evolution and likely related to $-\mathrm{COOH}$ reduction ${ }^{31}$, more pronounced in the more diluted electrolytes where water self-ionization (and thus $-\mathrm{COOH}$ formation) is more marked. The current and reduction potential both decrease with LiPAA content, either due to $\mathrm{PAA} / \mathrm{Li} / \mathrm{H}_{2} \mathrm{O}$ interactions, impaired PAA mobility or electrode passivation. Concerning the main oxidation and reductions reactions, a priori linked to water, the trend is rather obvious, with an increase of $300 \mathrm{mV}$ in the cathodic direction and of $400 \mathrm{mV}$ toward oxidation from ${ }^{14} \mathrm{wt} \%$ to $50 \mathrm{wt} \%$ LiPAA. Especially in the anodic direction, a steep increase is observed for the $50 \mathrm{wt} \%$ gel which, composition-wise, stands at the border of "water-insalt" and "salt-in-water" electrolytes ${ }^{15}$, suggesting a change in water $/ \mathrm{Li}^{+-} \mathrm{COO}^{-}$interactions and self-organization beyond this ratio.

Water interactions and structural evolutions. Water is both a donor and an acceptor solvent, because it interacts with the $\mathrm{Li}^{+}$ cation via its oxygen and with the carboxylate group via its hydrogens. To understand the effect of solvation on the electrochemical stability and local structure, quantum mechanical electronic structure calculations were combined with solid-state nuclear magnetic resonance (ssNMR) and X-ray and neutron scattering characterization (SAXS and WANS). Electrolytes from $84 \%$ LiPAA to $10 \%$ LiPAA were examined; and the number of $\mathrm{H}_{2} \mathrm{O}$ and $\mathrm{D}_{2} \mathrm{O}$ molecules per carboxylate for intermediate weight percentages is given in Supplementary Table 1 .

For modeling, we included a monomer of LiPAA $\left(\mathrm{CH}_{3} \mathrm{CH}_{2} \mathrm{COOLi}\right)$ and up to eight water molecules.

The details of the quantum mechanical simulations, optimized structures of $\mathrm{LiPAA}\left(\mathrm{H}_{2} \mathrm{O}\right)_{\mathrm{n}}(n=1-8)$ clusters, selected bond lengths, energies and free energies, as well as a more detailed analysis are given in Supplementary Note 4 and Supplementary Table 4). 


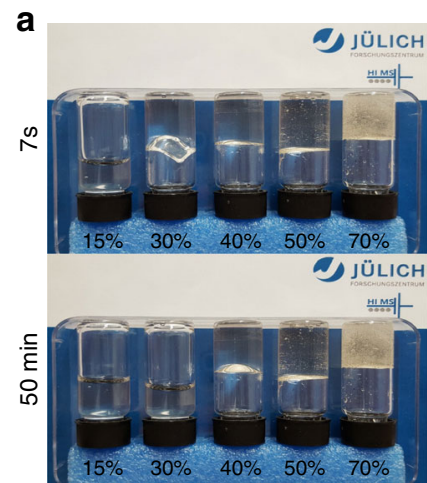

c

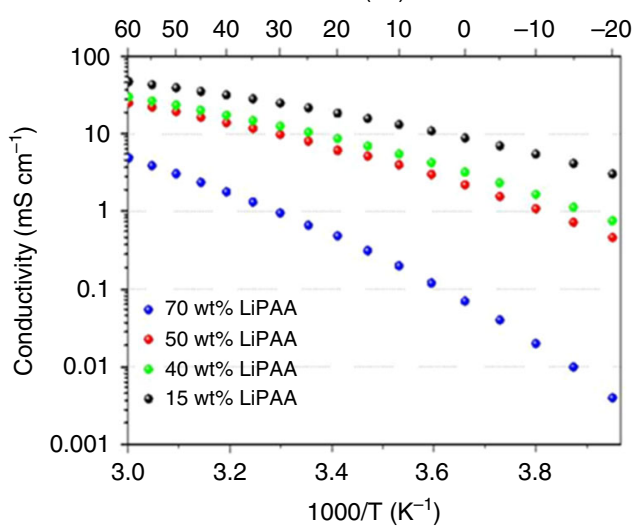

b

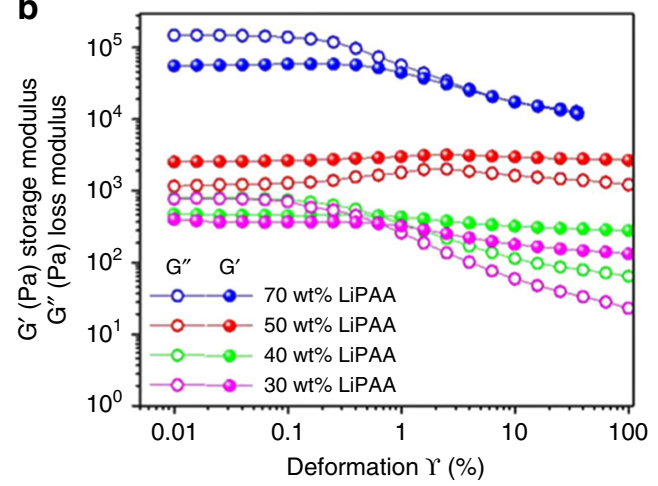

d

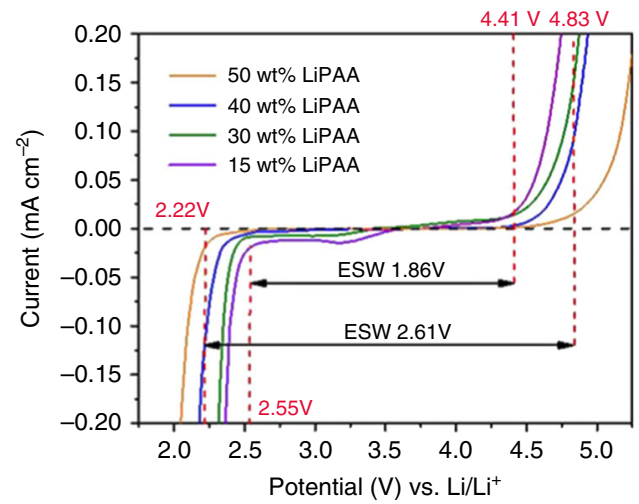

Fig. 1 Mechanical and electrochemical properties of the electrolytes. a Appearance of LiPAA aqueous electrolytes $7 \mathrm{~s}$ and 50 min after flipping the flasks. b Storage and loss moduli of the gel electrolytes (from 30 wt $\%$ to 70 wt\% LiPAA). c Arrhenius plot of the conductivities of the electrolytes. d Electrochemical stability window with Pt as the working electrode, scan rate: $0.1 \mathrm{mV} \mathrm{s}^{-1}$
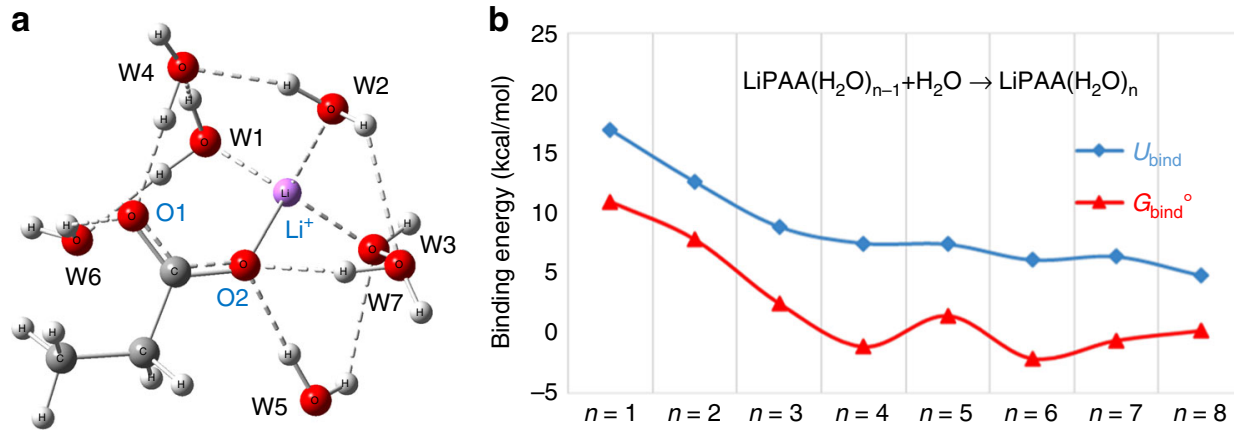

Fig. 2 Evolution of LiPAA solvation sphere. a Binding order of water molecules with LiPAA as calculated by M08-HX/MG3S/SMD. b Binding energies $\left(U_{\text {bind }}\right)$ and standard-state binding free energies $\left(G_{\text {bind }}{ }^{\circ}\right)$ of LiPAA $\left(\mathrm{H}_{2} \mathrm{O}\right)_{n}(n=1-8)$ as calculated by M08-HX/MG3S/SMD

Figure 2a shows the order in which water molecules would optimally add to a LiPAA monomer. The first two water molecules bind to $\mathrm{Li}^{+}$only, the third binds to $\mathrm{Li}^{+}$and carboxylate oxygens. From the fourth water molecules, $\mathrm{H}_{2} \mathrm{O}$ binds to - PAA and above six water molecules, they bind to carboxylate $\mathrm{O}$ and other water molecules. Finally, above eight water molecules, free water is present in all isomers.

Figure $2 \mathrm{~b}$ and Supplementary Table 4 show the binding energies and binding free energies of $\mathrm{LiPAA}\left(\mathrm{H}_{2} \mathrm{O}\right)_{n}(n=1-8)$. For $\operatorname{LiPAA}\left(\mathrm{H}_{2} \mathrm{O}\right)_{n}(n=1-4)$, the binding energy is gradually reduced as the number of water molecules increases. The binding free energy of the fourth through eighth water may be endergonic because of entropy effects and the gradual saturation of LiPAA.
To understand the role of electrostatics in the water binding process, charge model 5 (CM5) ${ }^{32}$ was used to determine the partial atomic charges on the $\mathrm{Li}^{+}$and the oxygen atoms in the clusters. The partial charge of the lithium ion decreases from 0.7 to 0.5 with increasing coordination of water in $\operatorname{LiPAA}\left(\mathrm{H}_{2} \mathrm{O}\right)_{\mathrm{n}} \quad(n=1-3)$. For $\operatorname{LiPAA}\left(\mathrm{H}_{2} \mathrm{O}\right)_{n} \quad(n=4-8)$, the negative charge of carboxylate oxygen atoms decreases with formation of hydrogen bonds between the $\mathrm{COO}^{-}$group and water molecules. This is consistent with the observed increase of anodic stability up to $50 \mathrm{wt} \%$ polymer as the water molecules, in this case, interact more with the oxygen atoms, which in turns results in an incremental increase in cathodic stability. 

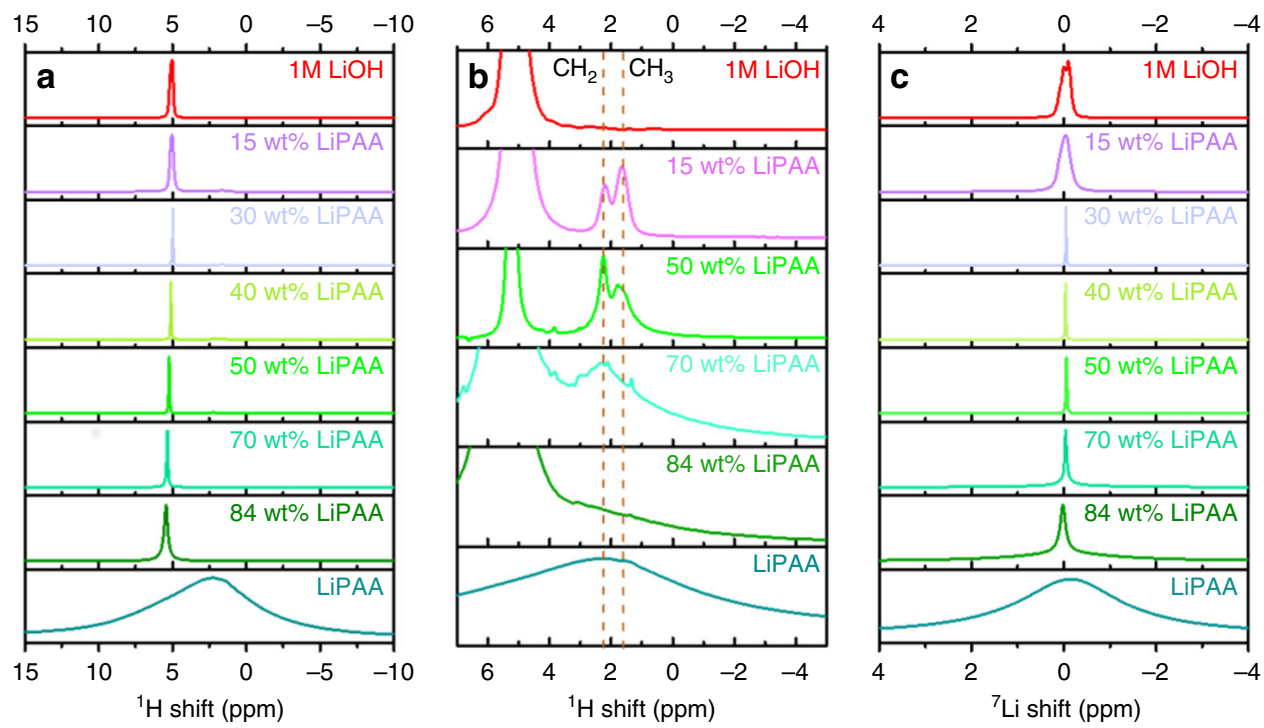

Fig. 3 MAS NMR spectra. a, b ${ }^{1} \mathrm{H}$ MAS NMR spectra of LiPAA/ $\mathrm{H}_{2} \mathrm{O}$ electrolytes, the dashed lines indicating the shift of the "water" resonance to lower frequency (blue) and the sharpening of the $\mathrm{CH}_{2}$ resonance (red) as the water content increases. $\mathbf{c}^{7} \mathrm{Li} \mathrm{MAS} N \mathrm{NMR}$ spectra of the LiPAA/H $\mathrm{H}_{2} \mathrm{O}$ electrolytes. All the LiPAA electrolyte spectra were acquired with a spinning rate of $14 \mathrm{kHz}$ while the spectra of $1 \mathrm{M} \mathrm{LiOH}$ solution was measured under static condition

Electrode passivation (i.e., the blocking of the active adsorption site for $\mathrm{H}_{2}$ evolution) by either adsorption of polymer or accumulation of reduction products, however, might also play a role in the ESW extension.

The interactions between water and LiPAA were probed via ${ }^{1} \mathrm{H}$ NMR and ${ }^{7} \mathrm{Li}$ NMR. LiPAA gives rise to a broad ${ }^{1} \mathrm{H}$ NMR (Fig. 3a) peak between 12 and $-8 \mathrm{ppm}$ that arises from the $\mathrm{CH}_{2}$ and $\mathrm{CH}_{3}$ groups in LiPAA, the restricted motion and consequently large ${ }^{1} \mathrm{H}$ dipole-dipole interactions, and the non-crystalline nature of the LiPAA (which will give rise to a distribution in chemical shifts) resulting in line broadening. The ${ }^{7} \mathrm{Li}$ (Fig. 3c) resonance of LiPAA is also broad indicating restricted $\mathrm{Li}^{+}$mobility. The addition of water results in a dramatic reduction in linewidths. As the amount of water in LiPAA increases, the resonances of $\mathrm{CH}_{2}(2.2 \mathrm{ppm})$ and $\mathrm{CH}_{3}$ (1.6 ppm) start to become better resolved, as marked in Fig. 3b, indicating that the water presumably decreases the packing density of the LiPAA and thus the $\mathrm{CH}_{2}$ and $\mathrm{CH}_{3}$ groups become more mobile. The shift of ${ }^{1} \mathrm{H}$ water in the $84 \mathrm{wt} \%$ sample is 0.6 $\mathrm{ppm}$ larger than that of free water $(4.8 \mathrm{ppm})^{33}$, suggesting that the water in the sample is bonded to $\mathrm{COO}^{-}$groups and the $\mathrm{Li}^{+}$ cations. When the LiPAA content decreases from $84 \mathrm{wt} \%$ to $30 \mathrm{wt} \%$, the viscosity of the electrolyte is reduced and the water ${ }^{1} \mathrm{H}$ resonance shifts to lower frequency and sharpens, presumably as the hydrogen bonding to the LiPAA $\mathrm{COO}^{-}$ groups decrease and the water intermolecular hydrogen bonding increases. The ${ }^{7} \mathrm{Li}$ resonance similarly sharpens as the mobility of the $\mathrm{Li}^{+}$ions increases. By $30 \mathrm{wt} \%$, both the ${ }^{1} \mathrm{H}$ "water" resonance and the ${ }^{7} \mathrm{Li}$ resonance are similar to those of the bulk $1 \mathrm{M} \mathrm{LiOH}$ resonances, indicating that free water and $\mathrm{Li}^{+}$ions are present. The peak widths of the $15 \mathrm{wt} \%$ sample and $1 \mathrm{M}$ aqueous $\mathrm{LiOH}{ }^{1} \mathrm{H}$ and ${ }^{7} \mathrm{Li}$ resonances are broader than that of the $30 \mathrm{wt} \%$ electrolyte, due to problems of shimming these samples in the wide bore magnet. Solution NMR experiments (Supplementary Fig. 1) with improved shimming showed that the linewidth of the ${ }^{1} \mathrm{H}$ (water) and ${ }^{7} \mathrm{Li}$ resonances were an order of magnitude narrower than those acquired on the ssNMR spectrometer (Supplementary Table 3), the resonances continuing to sharpen slightly from the 15 to $0 \mathrm{wt} \% \mathrm{LiPAA}$ samples. The ${ }^{17} \mathrm{O}$ NMR spectra of the $50 \mathrm{wt} \%$ sample also show a broad resonance at $0.3 \mathrm{ppm}$ (Supplementary Fig. 2), similar to the previous results reported for "water-in-salt" electrolyte ${ }^{20}$ suggesting that bound water is present in this $50 \mathrm{wt} \%$ sample.

Small angle X-ray scattering (SAXS) results shown in Supplementary Fig. 3, show one characteristic peak $\mathrm{q}_{1}$, corresponding to a distance $d_{1}$ which decreases with the polymer content (Fig. 4a). Thus it can be linked to the local structure, namely, the presence of hydrophilic domains, separated by the polymer chains. However, no second order peak can be seen, due to the lack of long-range order. Interestingly, the evolution of the distance $d_{1}$ with the LiPAA content seems to follow different slopes as the LiPAA content increases, which suggests that different local structural arrangements may correspond to each fraction of the curve, although the lack of second order signal does not allow concluding concerning their exact nature.

Wide angle neutron scattering (WANS) (Supplementary Fig. 4) measurements on LiPAA $/ \mathrm{D}_{2} \mathrm{O}$ samples reveal two other characteristic distances: A sharp peak $q_{2}$, at $1.27 \AA^{-1}\left(d_{2}=5 \AA\right)$ and a broader peak $q_{3}$ at $2.1 \AA^{-1}\left(d_{3}=3.0 \AA\right) . d_{2}$ corresponds to the distance between two consecutive carboxylate function facing the same direction on a straight polymer chain. It is not seen in the pure polymer, indicating that the polymer chains straighten to accommodate water. Figure $4 \mathrm{~b}$ shows the deviation to the general trend for the peak intensity. It can be seen that this linear LiPAA arrangement is far less marked for the $50 \mathrm{wt} \%$ sample $\left(3.9 \mathrm{D}_{2} \mathrm{O}\right.$ per $\left.\mathrm{Li}^{+}\right)$. The $50 \mathrm{wt} \%$ sample peculiar mechanical properties (elastic behavior on the whole range of deformation), as compared with the other samples, and well-preserved conductivity (vs. $40 \mathrm{wt} \%$ LiPAA) could possibly be due to an intermediate solvate structure (i.e., short range structuration) that would form around $50 \mathrm{wt} \%$, where polymer chains are less straight than at lower and higher contents.

The intensity of the broad $\mathrm{D}_{2} \mathrm{O}$ peak $q_{3}$ at $2.1 \AA^{-1}\left(d_{3}=3.0 \AA\right)$ is displayed as a function of the water content in Supplementary Fig. 5. Most of the data points follow a linear behavior that correlates with the linear decrease of hydrogen atoms in the sample. $d_{3}$, related to oxygen-oxygen correlation, evolves with water solvation and reaches a maximum of deviation to the trend for the 30\% LiPAA sample, indicating a maximum distortion of $\mathrm{D}_{2} \mathrm{O}$ organization for this water content. (i.e., for $9.1 \mathrm{D}_{2} \mathrm{O}$ per $\mathrm{Li}^{+}$). This would be due to its interaction with $-\mathrm{COO}-\mathrm{Li}$, while at higher LiPAA content, the intensity goes back to the linear trend. 

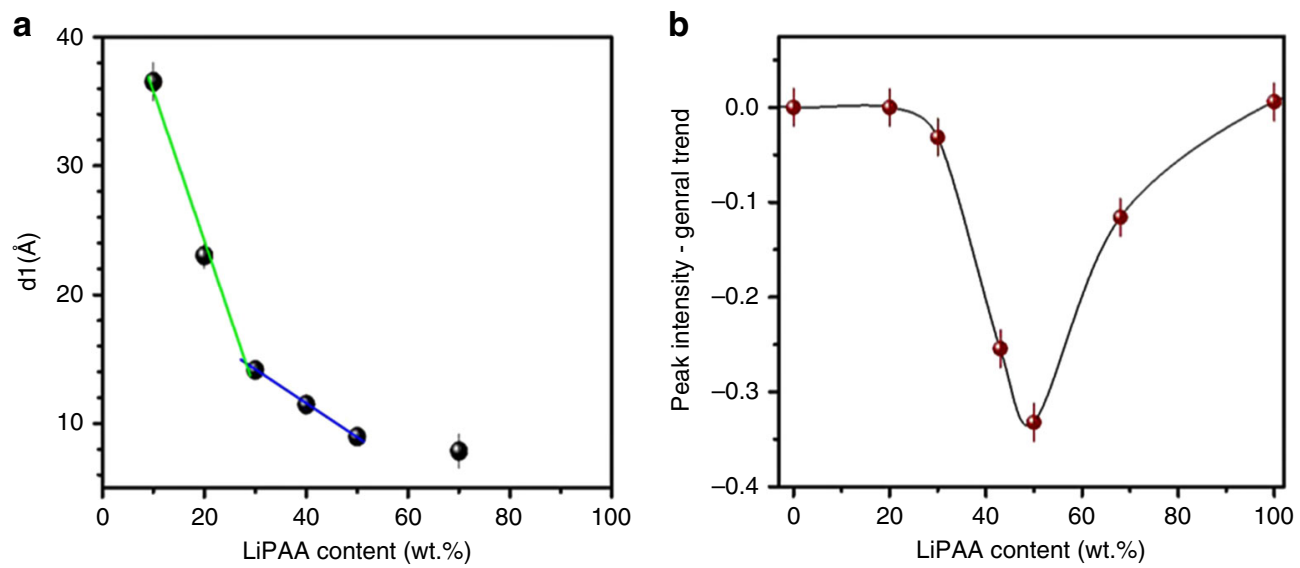

Fig. 4 Structural evolution of the electrolytes. a SAXS: Evolution of the correlation distances $d_{1}$ as a function of the LiPAA content in the electrolytes. b WANS: Deviation to the trend of the peak intensity for $q_{2}$ (at $1.27 \AA^{-1}, d_{2}=5 \AA$ ), displayed as a function of the LiPAA content in $D_{2} \mathrm{O}$ electrolyte

This maximum distortion of the water ordering is usually achieved by hydrogen bonding and lithium ion solvation. Below $70 \mathrm{wt} \%$ water content, the water is strongly coordinated to the polymer at the oxygen atoms and the lithium ion; at $70 \mathrm{wt} \%$ water content, the transition to free water molecules takes place and the structure is distorted most, while above $70 \mathrm{wt} \%$ water content, hydrogen bonding is facilitated again due to excess water.

Sustainable and nontoxic aqueous lithium-ion battery cells. Figure $5 \mathrm{a}$ shows the variation of the ESW of the $50 \mathrm{wt} \% \mathrm{LiPAA}$ electrolyte using $\mathrm{Pt}$, stainless steel (SS), and $\mathrm{Al}$ electrodes. As can be seen, Al, a typical current collector for Li-ion batteries, allows for an extended ESW as compared with Pt or stainless steel (SS). The electrolyte allows reversible insertion and deinsertion of lithium for both $\mathrm{TiO}_{2}$ and $\mathrm{LiTi}_{2}\left(\mathrm{PO}_{4}\right)_{3}$ anodes. For both electrodes, lithium electro(de)insertion occurs at the same potentials as in conventional organic electrolytes, contrary to $\mathrm{TiO}_{2}$ in more concentrated "water-in-salt" electrolytes ${ }^{23}$, which is advantageous in regard to energy density, but more challenging for the electrolyte. $\mathrm{LiMn}_{2} \mathrm{O}_{4}$ delithiation is reversible, but for $\mathrm{LiNi}_{0.5} \mathrm{Mn}_{1.5} \mathrm{O}_{4}$, only partial delithiation occurs on the reverse scan, probably due to extended self-discharge or other parasitic reactions such as $\mathrm{Al}$ anodic dissolution ${ }^{34}$ in the presence of $\mathrm{LiNi}_{0.5} \mathrm{Mn}_{1.5} \mathrm{O}_{4}$ in aqueous media. In fact, a prior study used $\mathrm{Ti}$ as current collector ${ }^{16}$.

Several lithium-ion cell chemistries were assembled using the $50 \mathrm{wt} \%$ LiPAA electrolyte. The electrochemical performance of a $\mathrm{TiO}_{2} / \mathrm{LiMn}_{2} \mathrm{O}_{4}$ cell is described in Supplementary Fig. 6. It delivered $59.2 \mathrm{mAh} \mathrm{g}^{-1}$ in the first cycle (with an average output voltage of $2.1 \mathrm{~V}$, corresponding to an energy density of $124.2 \mathrm{Wh}$ $\mathrm{kg}^{-1}$ ). The capacity of the cell decays rapidly, probably due to ineffective (slow) electrode passivation, before stabilizing. In fact, $\mathrm{TiO}_{2}$ is known to catalyze the decomposition of water ${ }^{35}$ and usually requires carbon coating for preventing direct contact with $\mathrm{H}_{2} \mathrm{O}^{36}$ and the active sites at its surface. However, the result compares favorably to previous results for non-carbon-coated $\mathrm{TiO}_{2}$ using a "water-in-salt" (LiTFSI-based) electrolyte ${ }^{23}$, both in terms of initial delivered capacity and cycling stability. While improvements are still necessary, the coulombic efficiency progressively increases to ca. $98 \%$, which indicates that electrode passivation occurs over cycling.

The performance of a $\mathrm{TiO}_{2} / \mathrm{LiNi}_{0.5} \mathrm{Mn}_{1.5} \mathrm{O}_{4}$ cell, cycled between $1.4 \mathrm{~V}$ to $3.2 \mathrm{~V}$ is shown in Supplementary Fig. 7. It delivered only a small fraction of its theoretical capacity (ca. $23 \mathrm{mAh} \mathrm{g}^{-1}$ for the full cell) and, despite an increase of coulombic efficiency with cycling, it only stabilizes to ca. $80 \%$, confirming the voltammetry results for $\mathrm{LiNi}_{0.5} \mathrm{Mn}_{1.5} \mathrm{O}_{4}$. Given that some water in the electrolyte does not interact with $\mathrm{Li}^{+}$, but rather with $\mathrm{COO}^{-}$, which has a priori a limited effect on the anodic stability, it seems that the practical gain in anodic stability are limited for the $50 \mathrm{wt} \%$ LiPAA electrolyte, even though some cycling at $3.2 \mathrm{~V}$ is possible.

\section{Discussion}

Figure 5b compares the thermodynamic ESW of water with the end-of-charge voltages reached with different aqueous Li-ion battery chemistries and either conventional "salt-in-water" aqueous electrolyte with inorganic salts or "water-in-salt" electrolytes with fluorinated salts and the LiPAA $50 \mathrm{wt} \%$ electrolyte ("waterin-ionomer" electrolyte) in a $\mathrm{TiO}_{2} / \mathrm{LiMn}_{2} \mathrm{O}_{4}$ cell. For the latter, the enlargement of the ESW window is mainly due to gains in cathodic stability, which is the main challenge for aqueous electrolytes. On the other hand, fluorinated "water-in-salt" electrolytes allow better anodic stability due to the stronger interactions of water, present in lower amounts, with the $\mathrm{Li}^{+}$ions.

The best cycling stability, shown in Fig. $5 \mathrm{c}$ was reached for a $\mathrm{LiTi}_{2}\left(\mathrm{PO}_{4}\right)_{3} / \mathrm{LiMn}_{2} \mathrm{O}_{4}$ cell, which delivered rather stable capacities for 100 cycles with an initial energy density of $77 \mathrm{Wh} \mathrm{kg}^{-1}$ and a remarkable capacity retention over 100 cycles. The voltage profiles are hardly affected by the cycling, and efficiencies are close to $100 \%$ after stabilization ( $>98.0 \%$ from cycle 35 and up to 98.5\%). The same cell chemistry cycled using a $40 \mathrm{wt} \%$ LiPAA electrolyte is shown in Supplementary Figs. 8-9. The capacity decay is far more marked with only a $77 \%$ capacity retention within 100 cycles. Figure 5d compares different aqueous battery chemistries in terms of energy density and average output voltages. The energy density $\left(77 \mathrm{Wh} \mathrm{kg}^{-1}\right)$ reached with $\mathrm{LiTi}_{2}\left(\mathrm{PO}_{4}\right)_{3} / \mathrm{LiMn}_{2} \mathrm{O}_{4}$ cells is higher than those generally achieved with similar electrode chemistries in conventional aqueous electrolytes due to a favorable electrode weight ratio and a high-discharge voltage allowed by the high rate capability of the electrolyte and the $\operatorname{LiTi}_{2}\left(\mathrm{PO}_{4}\right)_{3}$ electrode. On the other hand, the $\mathrm{TiO}_{2} / \mathrm{LiMn}_{2} \mathrm{O}_{4}$ battery compares well with those obtained with concentrated fluorinated anions.

In summary, the series of aqueous electrolytes, based on the nontoxic ionomer LiPAA opens a range of possibilities in the search for new, cheap, safe, and environmentally benign electrolytes for LIB systems. The electrolyte containing $50 \mathrm{wt} \% \mathrm{LiPAA}$ is a leak-free and dimensionally stable gel electrolyte that exhibits a high conductivity as well as a "water-in-ionomer" behavior, with a particularly noticeable enlargement of the ESW. It allows the design of environmentally friendly battery cell chemistries, free of 


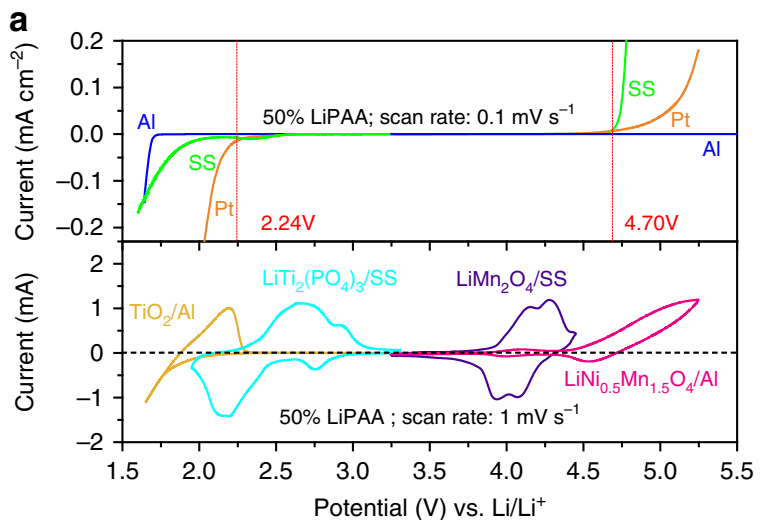

b
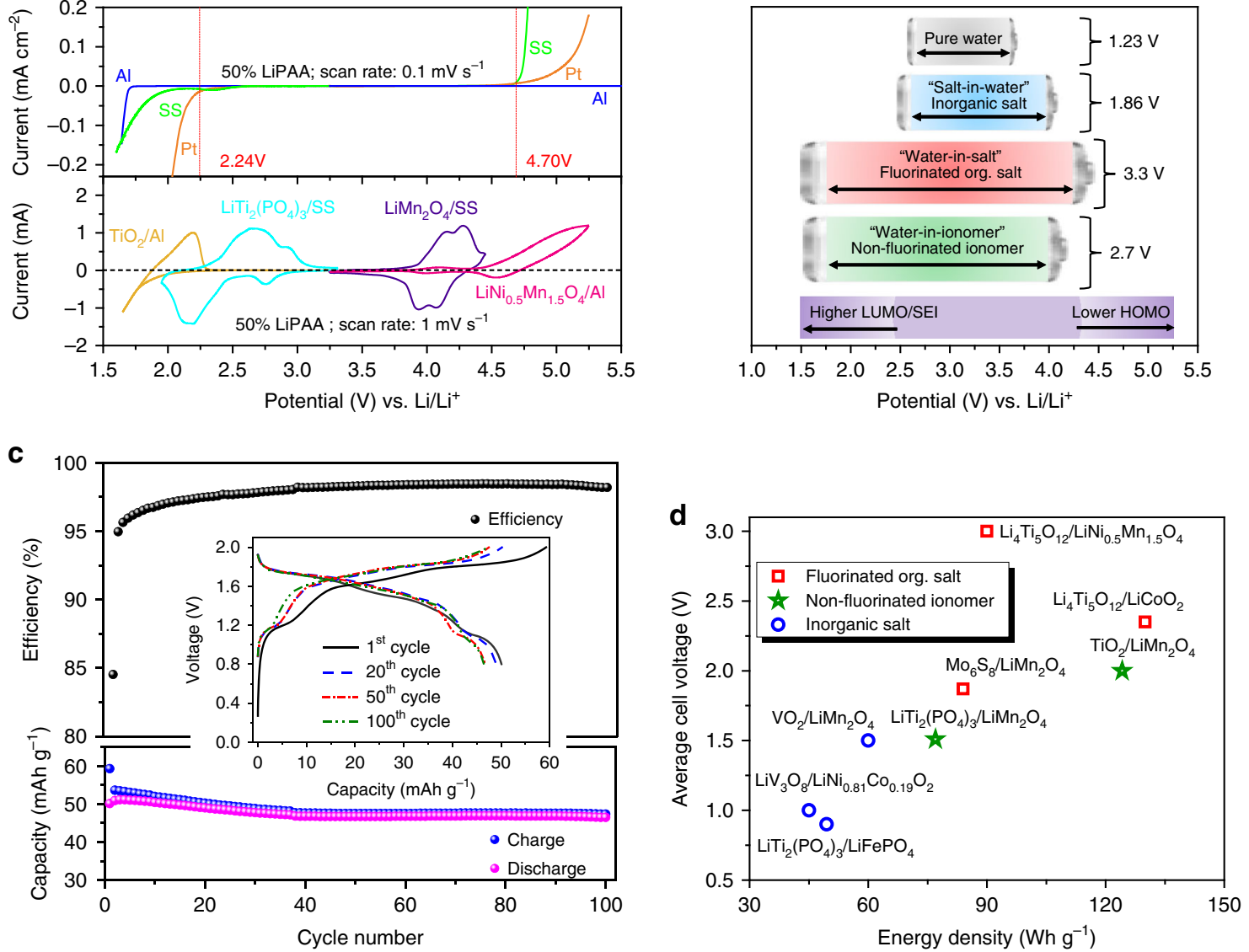

Fig. 5 50wt\% 'water-in-ionomer' gel as lithium-ion electrolyte. a Electrochemical stability windows of the 50 wt\% LiPAA electrolyte measured on Pt, stainless steel (SS) and $\mathrm{Al}$ as well as cyclic voltammograms of $\mathrm{TiO}_{2}, \mathrm{LiTi}_{2}\left(\mathrm{PO}_{4}\right)_{3}$, $\mathrm{LiMn}_{2} \mathrm{O}_{4}$ and $\mathrm{LiNi}_{0.5} \mathrm{Mnn}_{1.5} \mathrm{O}_{4}$ on various current collectors as indicated in the graph. Scan rate: $0.1 \mathrm{mV} \mathrm{s}^{-1}$. b Comparison of aqueous lithium-ion battery end-of-charge voltages with various salts. The "salt-in-water" electrolyte correspond to $1 \mathrm{M} \mathrm{Li}_{2} \mathrm{SO}_{4}$ in a $\mathrm{LiTi}_{2}\left(\mathrm{PO}_{4}\right)_{3} / \mathrm{LiMn}_{2} \mathrm{O}_{4}$ cell ${ }^{39}$, the "water-in-salt electrolyte" corresponds to $\mathrm{Li}\left(\mathrm{TFSI}_{0.7}(\mathrm{BETI})_{0.3} \cdot 2 \mathrm{H}_{2} \mathrm{O}\right.$ in a $\mathrm{Li}_{4} \mathrm{Ti}_{5} \mathrm{O}_{12} /$ $\mathrm{LiNi}_{0.5} \mathrm{Mn}_{1.5} \mathrm{O}_{4}$ cell22, and the "water-in-ionomer" corresponds to the $50 \mathrm{wt} \% \mathrm{LiPAA}$ gel electrolyte in a $\mathrm{TiO}_{2} / \mathrm{LiMn}_{2} \mathrm{O}_{4}$ cell. c. Evolution of specific capacities and coulombic efficiencies of a $\mathrm{LiTi}_{2}\left(\mathrm{PO}_{4}\right)_{3} / \mathrm{LiMn}_{2} \mathrm{O}_{4}$ battery cell at $0.5 \mathrm{C}$. Current collectors: SS. The weight refers to both electrodes. Insert: Voltage profiles for selected cycles as indicated on the graph. $\mathbf{d}$ Performance data of aqueous lithium-ion batteries based on various electrochemical couples. $\mathrm{LiTi}_{2}\left(\mathrm{PO}_{4}\right)_{3} / \mathrm{LiFePO}_{4}{ }^{40}, \mathrm{LiV}_{3} \mathrm{O}_{8} / \mathrm{LiNi}_{0.81} \mathrm{Co}_{0.19} \mathrm{O}_{2}{ }^{41}, \mathrm{VO}_{2} / \mathrm{LiMn}_{2} \mathrm{O}_{4}{ }^{18}, \mathrm{Mo}_{6} \mathrm{~S}_{8} / \mathrm{LiMn}_{2} \mathrm{O}_{4}{ }^{20}, \mathrm{Li}_{4} \mathrm{Ti}_{5} \mathrm{O}_{12} / \mathrm{LiCoO}_{2}$ and $\mathrm{Li}_{4} \mathrm{Ti}_{5} \mathrm{O}_{12} / \mathrm{LiNi}_{0.5} \mathrm{Mn}_{1.5} \mathrm{O}_{4}{ }^{22}$. Insert: Energy densities for selected aqueous electrolytes for $\mathrm{LiTi}_{2}\left(\mathrm{PO}_{4}\right)_{3} / \mathrm{LiMn}_{2} \mathrm{O}_{4}$ couple. 50 wt\% LiPAA, 5M LiNO ${ }_{3}^{42}, 2 \mathrm{M} \mathrm{Li}_{2} \mathrm{SO}_{4}{ }^{43}, 1 \mathrm{M} \mathrm{Li}_{2} \mathrm{SO}_{4}{ }^{45}$

nickel, cobalt, and fluorine, which can be operated up to $2.7 \mathrm{~V}$ with an initial energy density of $124 \mathrm{Wh} \mathrm{kg}^{-1}$ at the material level. It is worth mentioning that, if the most recent $\mathrm{NiMH}$ batteries have a specific energy of ca. $100 \mathrm{Wh} \mathrm{kg}^{-1}$, they could only store $54 \mathrm{Wh} \mathrm{kg}^{-1}$ at their commercial release ${ }^{37}$ and the earliest Li-ion batteries could only deliver $80 \mathrm{Wh} \mathrm{kg}^{-1}$ (vs. $250 \mathrm{Wh} \mathrm{kg}^{-1}$ for the most recent ones) ${ }^{38}$. Thus, the electrolyte concept developed in this study represents a step forward to a truly sustainable and nontoxic aqueous Li-ion battery with high energy density.

\section{Methods}

Electrode materials. The cathode materials (spinel $\mathrm{LiMn}_{2} \mathrm{O}_{4}$ and $\mathrm{LiNi}_{0.5} \mathrm{Mn}_{1.5} \mathrm{O}_{4}$ ) were purchased from Shanshan Technology Corporation and used without further purification. $\mathrm{LiTi}_{2}\left(\mathrm{PO}_{4}\right)_{3}$ was synthesized by a phytic acid assisted solid-state method. In total, $17 \mathrm{~mL}$ tetrabutyl titanate $\left(\mathrm{Ti}\left(\mathrm{OC}_{4} \mathrm{H}_{9}\right)_{4}, \mathrm{TBT}\right)$ was first added to $500 \mathrm{~mL}$ of mixed butyl/ethanol (3:7 in volume ratio) solution under constant stirring to form white suspension. After stirring for $0.5 \mathrm{~h}, 3.12 \mathrm{~g}$ of lithium dihydrogen phosphate $\left(\mathrm{LiH}_{2} \mathrm{PO}_{4}\right)$ which was dissolved in $10 \mathrm{~mL}$ of distilled water and $9.25 \mathrm{~mL}$ of physic acid (50 wt\% in water) were added to the solution. The mixed solution was further stirred at room temperature for $4 \mathrm{~h}$. The collected precipitate was washed with ethanol and distilled water, followed by drying at $80^{\circ} \mathrm{C}$ to form the precursor. The LTP/C composite was obtained by heating the as-prepared precursor at $750{ }^{\circ} \mathrm{C}$ for $4 \mathrm{~h}$ under argon atmosphere. In a typical sythesis process of
$\mathrm{TiO}_{2}, 120 \mathrm{~mL}$ of ethanol solution containing $20 \mathrm{~g}$ of tetrabutyl titanate and $1.2 \mathrm{~g}$ of acetic acid was dropwise added into $240 \mathrm{~mL}$ of water/ethanol solution $(3: 1$ in volume ratio) containing $8 \mathrm{~g}$ of oxalic acid (OA) and $0.8 \mathrm{~g}$ of sodium dodecylbenzenesulfonate (SDBS) under stirring at room temperature. The resulting light brown slurry was further stirred for $3 \mathrm{~h}$ and additionally aged for $1 \mathrm{~h}$. The precipitate was collected by centrifuge and repeatedly washed with ethanol and deionized water, and then dried at $80^{\circ} \mathrm{C}$. The obtained nanocomposite was further calcined at $600^{\circ} \mathrm{C}$ for $5 \mathrm{~h}$ under air, resulting in the $\mathrm{TiO}_{2}$ product. The morphologies and structures of these materials are confirmed by SEM and XRD, shown in Supplementary Figs. 10 and 11.

Aqueous electrolyte. The lithium salt of poly(acrylic acid) was prepared by equilibrating the linear polymer $(200 \mathrm{ml}, 30 \%$ in water solution, $\mathrm{Mw}=250,000)$ with dilute lithium hydroxide solution $\left(0.05 \mathrm{~mol} \mathrm{~L}^{-1}\right)$. Until the $\mathrm{pH}$ value became neutral, the neutral solution was kept constant stirring for $24 \mathrm{~h}$. The functionalized polymer was obtained after all the water was evaporated at $80^{\circ} \mathrm{C}$. The electrolytes were then prepared by adding appropriate amounts of deionized water.

Electrode material characterization. The crystal structure of the prepared materials was characterized by X-ray diffraction (XRD) on a Bruker D8 Advance (Bruker) diffractometer with $\mathrm{Cu} \mathrm{K}$ radiation $(1.54 \AA$ ) at room temperature. The pattern was recorded in the $2 \theta$ range of $10-90^{\circ}$ at a scan rate of $0.0197^{\circ}$ per step and a count time per step of $1 \mathrm{~s}$. The particle morphology was evaluated using fieldemission scanning electron microscopy (FE-SEM, Zeiss Auriga). The SEM images 
and XRD patterns of LiMn2O4, $\mathrm{LiNi}_{0.5} \mathrm{Mn}_{1.5} \mathrm{O} 4, \mathrm{LiTi}_{2}\left(\mathrm{PO}_{4}\right)_{3}$, and $\mathrm{TiO}_{2}$ materials are showed in Supplementary Figs. 9 and 10.

Electrochemical measurements. The slurry to prepare the electrodes was obtained by mixing the active materials, conductive carbon (Super C65, Timcal), and a binder (polyvinylidene difluoride PVdF, Kynar ${ }^{\oplus}$ FLEX 2801, Arkema Group) in a weight ratio of 80:12.5:7.5, with $N$-methyl-2-pyrrolidone (NMP) as the processing solvent. The well-mixed slurry was coated on a $\mathrm{Cu}$ foil and dried at $80^{\circ} \mathrm{C}$ overnight. After being punched into $\varnothing 13 \mathrm{~mm}$ discs, the electrodes (of ca. $4-5 \mathrm{mg} \mathrm{cm}^{-2}$, with cathode capacities of ca. $80 \%$ of that of the anodes) were further pressed on $\varnothing 12 \mathrm{~mm}$ steel/aluminum mesh. The $\mathrm{Cu}$ foil was then removed and the electrodes were dried for $12 \mathrm{~h}$ under vacuum at $100^{\circ} \mathrm{C}$. The electrochemical performance was evaluated with a Swaglok cell system. The cathode and anode were separated by glass fiber (Whatman GF/D) impregnated with $1 \mathrm{~mL}$ of the electrolytes. Galvanostatic cycling tests were carried out on MACCOR series 4000 battery testers at various current rates.

\section{Data availability}

The data generated during the current study are available from the corresponding author on reasonable request.

Received: 14 November 2017 Accepted: 28 October 2018

Published online: 14 December 2018

\section{References}

1. Wagner, R., Preschitschek, N., Passerini, S., Leker, J. \& Winter, M. Current research trends and prospects among the various materials and designs used in lithium-based batteries. J. Appl. Electrochem. 43, 481-496 (2013).

2. Lebedeva, N. P. \& Boon-Brett, L. Considerations on the chemical toxicity of contemporary Li-ion battery electrolytes and their components. J. Electrochem. Soc. 163, A821-A830 (2016).

3. Tsuchida, E., Ohno, H. \& Kobayashi, N. Single-ion conduction in poly [(oligo (oxyethylene) methacrylate)-co-(alkali-metal methacrylates)]. Macromolecules 21, 96-100 (1988).

4. Jeong, S.-K., Inaba, M., Iriyama, Y., Abe, T. \& Ogumi, Z. Electrochemical intercalation of lithium ion within graphite from propylene carbonate solutions. Electrochem. Solid-State Lett. 6, A13-A15 (2003).

5. Angell, C., Liu, C. \& Sanchez, E. Rubbery solid electrolytes with dominant cationic transport and high ambient conductivity. Nature 362, 137-139 (1993).

6. Angell, C. A. Electrical conductance of concentrated aqueous solutions and molten salts: correlation through free volume transport model. J. Phys. Chem. 69, 2137-2137 (1965).

7. Croce, F., Settimi, L., Scrosati, B. \& Zane, D. Nanocomposite, PEO-LiBOB polymer electrolytes for low temperature, lithium rechargeable batteries. $J$. New Mater. Electrochem. Syst. 9, 3 (2006).

8. Egashira, M., Scrosati, B., Armand, M., Béranger, S. \& Michot, C. Lithium dicyanotriazolate as a lithium salt for poly (ethylene oxide) based polymer electrolytes. Electrochem. Solid-State Lett. 6, A71-A73 (2003).

9. Johansson, P., Nilsson, H., Jacobsson, P. \& Armand, M. Novel Hückel stabilised azole ring-based lithium salts studied by ab initio Gaussian-3 theory. Phys. Chem. Chem. Phys. 6, 895-899 (2004).

10. Paillard, E., Alloin, F., Cointeaux, L., Iojoiu, C. \& Sanchez, J.-Y. Poly (oxyethylene) electrolytes based on lithium nitrophenyl sulfonamide and hexanitrodiphenylamide. Electrochim. Acta 57, 20-26 (2011).

11. Scheers, J. et al. All fluorine-free lithium battery electrolytes. J. Power Sources 251, 451-458 (2014).

12. Xu, K., Zhang, S. \& Jow, T. R. Formation of the graphite/electrolyte interface by lithium bis(oxalato)borate. Electrochem. Solid-State Lett. 6, A117-A120 (2003).

13. Tamura, T. et al. Physicochemical properties of glyme-Li salt complexes as a new family of room-temperature ionic liquids. Chem. Lett. 39, 753-755 (2010).

14. Yoshida, K. et al. Oxidative-stability enhancement and charge transport mechanism in glyme-lithium salt equimolar complexes. J. Am. Chem. Soc. 133, 13121-13129 (2011)

15. Suo, L., Hu, Y.-S., Li, H., Armand, M. \& Chen, L. A new class of solvent-in-salt electrolyte for high-energy rechargeable metallic lithium batteries. Nat. Commun. 4, 1481 (2013).

16. Yamada, Y. et al. Unusual stability of acetonitrile-based superconcentrated electrolytes for fast-charging lithium-ion batteries. J. Am. Chem. Soc. 136, 5039-5046 (2014).
17. Renault, S., Brandell, D. \& Edström, K. Environmentally-friendly lithium recycling from a spent organic Li-ion battery. ChemSusChem 7, 2859-2867 (2014).

18. Li, W., Dahn, J. R. \& Wainwright, D. S. Rechargeable lithium batteries with aqueous electrolytes. Science 264, 1115-1117 (1994).

19. Wang, G. X., Zhong, S., Bradhurst, D. H., Dou, S. X. \& Liu, H. K. Secondary aqueous lithium-ion batteries with spinel anodes and cathodes. J. Power Sources 74, 198-201 (1998)

20. Suo, L. et al. "Water-in-salt" electrolyte enables high-voltage aqueous lithiumion chemistries. Science 350, 938-943 (2015).

21. Dong, X. et al. All-organic rechargeable battery with reversibility supported by "water-in-salt" electrolyte. Chem. Eur. J. 23, 2560-2565 (2017).

22. Yamada, Y. et al. Hydrate-melt electrolytes for high-energy-density aqueous batteries. Nat. Energy 1, 16129 (2016)

23. Suo, L. et al. Advanced high-voltage aqueous lithium-ion battery enabled by "water-in-bisalt" electrolyte. Angew. Chem. 128, 7252-7257 (2016).

24. Hardy, L. C. \& Shriver, D. F. Preparation and electrical response of solid polymer electrolytes with only one mobile species. J. Am. Chem. Soc. 107, 3823-3828 (1985)

25. Benrabah, D., Sylla, S., Alloin, F., Sanchez, J.-Y. \& Armand, M. Perfluorosulfonate-polyether based single ion conductors. Electrochim. Acta 40, 2259-2264 (1995).

26. Tsuchida, E., Ohno, H., Kobayashi, N. \& Ishizaka, H. Poly [(ı-carboxy) oligo (oxyethylene) methacrylate] as a new type of polymeric solid electrolyte for alkali-metal ion transport. Macromolecules 22, 1771-1775 (1989).

27. Bouchet, R. et al. Single-ion BAB triblock copolymers as highly efficient electrolytes for lithium-metal batteries. Nat. Mater. 12, 452-457 (2013).

28. Thomas, K. E., Sloop, S. E., Kerr, J. B. \& Newman, J. Comparison of lithiumpolymer cell performance with unity and nonunity transference numbers. $J$. Power Sources 89, 132-138 (2000).

29. CFR - Code of Federal Regulations Title 21, Volume 3. available at: https:// www.accessdata.fda.gov/scripts/cdrh/cfdocs/cfcfr/CFRSearch.cfm?fr=173.73 (2018).

30. Cekic-Laskovic, I. et al. Synergistic effect of blended components in nonaqueous electrolytes for lithium ion batteries. Top. Curr. Chem. 375, 37 (2017).

31. Hodgman, C. D. Handbook of chemistry and physics Ch.5 (CRC Press, 91st edition, 2010)

32. Marenich, A. V., Jerome, S. V., Cramer, C. J. \& Truhlar, D. G. Charge Model 5 an extension of hirshfeld population analysis for the accurate description of molecular interactions in gaseous and condensed phases. J. Chem. Theory Comput. 8, 527-541 (2012)

33. Hunger, M., Freude, D. \& Pfeifer, H. Magic-angle spinning nuclear magnetic resonance studies of water molecules adsorbed on Bronsted- and Lewis-acid sites in zeolites and amorphous silica-aluminas. J. Chem. Soc., Faraday Trans. 87, 657-662 (1991).

34. Krämer, E. et al. Mechanism of anodic dissolution of the aluminum current collector in 1M LiTFSI EC: DEC 3: 7 in rechargeable lithium batterie. S. J. Electrochem. Soc. 160, A356-A360 (2013).

35. Wang, Z.-T. et al. Probing equilibrium of molecular and deprotonated water on $\mathrm{TiO}_{2}$ (110). Proc. Natl. Acad. Sci. USA 114, 1801-1805 (2017).

36. Suo, L. et al. Advanced high-voltage aqueous lithium-ion battery enabled by "water-in-bisalt" electrolyte. Angew. Chem. Int. Ed. 55, 7136-7141 (2016).

37. Fetcenko, M. A. et al. Recent advances in NiMH battery technology. J. Power Sources 165, 544-551 (2007).

38. Blomgren, G. E. The development and future of lithium ion batteries. J. Electrochem. Soc. 164, A5019-A5025 (2017).

39. Luo, J. \& Xia, Y. Aqueous lithium-ion battery $\mathrm{LiTi}_{2}\left(\mathrm{PO}_{4}\right)_{3} / \mathrm{LiMn}_{2} \mathrm{O}_{4}$ with high power and energy densities as well as superior cycling stability. Adv. Funct. Mater. 17, 3877-3884 (2007).

40. Luo, J., Cui, W., He, P. \& Xia, Y. Raising the cycling stability of aqueous lithium-ion batteries by eliminating oxygen in the electrolyte. Natur. Chem. 2, 760-765 (2010).

41. Köhler, J., Makihara, H., Uegaito, H., Inoue, H. \& Toki, M. $\mathrm{LiV}_{3} \mathrm{O}_{8}$ : characterization as anode material for an aqueous rechargeable Li-ion battery system. Electrochim. Acta 46, 59-65 (2000).

42. Wang, H., Huang, K., Zeng, Y., Yang, S. \& Chen, L. Electrochemical properties of $\mathrm{TiP}_{2} \mathrm{O}_{7}$ and $\mathrm{LiTi}_{2}\left(\mathrm{PO}_{4}\right)_{3}$ as anode material for lithium ion battery with aqueous solution electrolyte. Electrochim. Acta 52, 3280-3285 (2007).

43. Liu, Z., Qin, X., Xu, H. \& Chen, G. One-pot synthesis of carbon-coated nanosized $\mathrm{LiTi}_{2}\left(\mathrm{PO}_{4}\right)_{3}$ as anode materials for aqueous lithium ion batteries. $J$. Power Sources 293, 562-569 (2015).

44. Cui, Y. et al. Synthesis and electrochemical behavior of $\mathrm{LiTi}_{2}\left(\mathrm{PO}_{4}\right)_{3}$ as anode materials for aqueous rechargeable lithium batteries. J. Electrochem. Soc. 160, A53-A59 (2013). 


\section{Acknowledgements}

Jie $\mathrm{Li}$ and Jun Wang acknowledge the funding from the German federal ministries of education and research (BMBF), of economics technology and environment (BMWi), of nature preservation and nuclear safety (BMU) within the project KaLiPat (03EK3008). Dominic Bresser would like to acknowledge the NanoSciences Programme (CEA) and the EU/CEA Enhanced Eurotalents Fellowship for financial support. Moreover, Dominic Bresser would like to thank Dr. Alain Farchi for his support with setting up the SAXS experiments. Zigeng Liu would like to thank Yanting Jin for the measurement of samples with solution NMR. We thank Margarita Kruteva for supporting the SAXS measurements on GALAXI.

\section{Author contributions}

X.H. and J.L. proposed the concept. X.H. and E.P. designed the study and prepared the paper with contribution from all authors. X.H. and B.Y. synthesized $\operatorname{LiTi}_{2}\left(\mathrm{PO}_{4}\right)_{3}$. J.W synthesized $\mathrm{TiO}_{2}$. X.Z. and D.G.T. performed the theoretical calculations. Z.L. and C.P.G. performed NMR and analyzed the results. R.W., Y.S. and H.F. performed and analyzed WANS and SAXS results. Dominic Bresser performed SAXS and analyzed the results. X.C. performed conductivity measurements. H.J. and M.W. took part in the discussion.

\section{Additional information}

Supplementary Information accompanies this paper at https://doi.org/10.1038/s41467018-07331-6.
Competing interests: The authors declare no competing interests.

Reprints and permission information is available online at http://npg.nature.com/ reprintsandpermissions/

Publisher's note: Springer Nature remains neutral with regard to jurisdictional claims in published maps and institutional affiliations.

(c) (i) Open Access This article is licensed under a Creative Commons Attribution 4.0 International License, which permits use, sharing, adaptation, distribution and reproduction in any medium or format, as long as you give appropriate credit to the original author(s) and the source, provide a link to the Creative Commons license, and indicate if changes were made. The images or other third party material in this article are included in the article's Creative Commons license, unles indicated otherwise in a credit line to the material. If material is not included in the article's Creative Commons license and your intended use is not permitted by statutory regulation or exceeds the permitted use, you will need to obtain permission directly from the copyright holder. To view a copy of this license, visit http://creativecommons.org/ licenses/by/4.0/.

(c) The Author(s) 2018 